\title{
Environmental heterogeneity at small spatial scales affects population and community dynamics on intertidal rocky shores of a threatened bay system
}

Dias, Gustavo; Christofoletti, Ronaldo; Kitazawa, K; Jenkins, Stuart

\section{Ocean and Coastal Management}

DOI:

10.1016/j.ocecoaman.2017.12.001

Published: 01/10/2018

Peer reviewed version

Cyswllt i'r cyhoeddiad / Link to publication

Dyfyniad o'r fersiwn a gyhoeddwyd / Citation for published version (APA):

Dias, G., Christofoletti, R., Kitazawa, K., \& Jenkins, S. (2018). Environmental heterogeneity at small spatial scales affects population and community dynamics on intertidal rocky shores of a threatened bay system. Ocean and Coastal Management, 164, 52-59.

https://doi.org/10.1016/j.ocecoaman.2017.12.001

\section{Hawliau Cyffredinol / General rights}

Copyright and moral rights for the publications made accessible in the public portal are retained by the authors and/or other copyright owners and it is a condition of accessing publications that users recognise and abide by the legal requirements associated with these rights.

- Users may download and print one copy of any publication from the public portal for the purpose of private study or research.

- You may not further distribute the material or use it for any profit-making activity or commercial gain

- You may freely distribute the URL identifying the publication in the public portal ?

Take down policy

If you believe that this document breaches copyright please contact us providing details, and we will remove access to the work immediately and investigate your claim. 
Title: Environmental heterogeneity at small spatial scales affects population and community dynamics on intertidal rocky shores of a threatened bay system

Authors: Gustavo M Dias, ${ }^{1, *}$, Ronaldo A Christofoletti ${ }^{2}$, Karina Kitazawa ${ }^{1}$, Stuart R Jenkins $^{3}$

${ }^{1}$ Center of Natural and Human Sciences, Federal University of ABC (CCNH/UFABC), Rua Santa Adélia, 166, Santo Andre SP 09210170, Brazil

${ }^{2}$ Institute of Marine Sciences, Federal University of São Paulo (IMar/UNIFESP), Rua Dr Carvalho de Mendonça 144, Santos, SP 11070-100, Brazil

${ }^{3}$ School of Ocean Sciences, Bangor University, Menai Bridge Anglesey LL59 5AB, UK

* corresponding author: gmdias@ufabc.edu.br

\begin{abstract}
Coastal areas are critical transition zones between marine and terrestrial domains that support a large diversity of species but are exposed to significant anthropogenic impacts. While most conservation and management strategies rely on understanding the drivers of diversity over large scales, the importance of small-scale variation in environmental conditions can be overlooked. Here we combined a descriptive and experimental approach to describe the spatio-temporal dynamics of sessile communities and of the population of the barnacle Chthamalus bisinuatus within Araçá Bay, a transition zone in southeastern Brazil threatened by the expansion of the São Sebastião Port. We compared the relative coverage of sessile organisms from rocky shores for 20 months and several population parameters of barnacles in three distinct regions of Araçá Bay, a few hundred meters apart: the inner portion, close to the Mãe Isabel River and the Port, the middle of the Bay, and the outer region, close
\end{abstract}


to the bay entrance. Community structure varied significantly over these small spatial scales; the macroalga Ulva lactuca and the oyster Crassostrea sp. were more abundant in the inner portion of the Bay, where the influence of freshwater and organic pollution from Mãe Isabel River is more intense. Recruitment and density of C. bisinuatus was higher on the shores close to the mouth of the Bay, but individual size increased as one moves into the bay. Experimental manipulation of barnacles originally recruiting at the outer part of the bay and translocated to both outer and inner positions showed that while recruitment is restricted at the inner region, barnacle growth and survival are higher than at the outer shore. Our results suggest that the gradient of physical conditions created along the Araçá Bay can result in distinct dynamics of communities and populations and that the region close to the mouth of the bay is more dynamic, with a larger turnover of space. In the opposite direction, the inner part of the bay, which is closer to the São Sebastião Port, is more prone to be disturbed by any large human modification on the coast as populations are less dynamic and communities tend to be monopolized by species associated with organic pollution. Besides providing useful data for the management of Araçá Bay, our results also show that small-scale variation of environmental conditions can contribute to create distinct dynamics of populations and communities and should be addressed in assessments of environmental impacts on the coast. 


\section{INTRODUCTION}

Coastal areas are important systems for studies on the influence of natural and anthropogenic drivers of biodiversity. The biological processes operating in the transition zone between terrestrial and marine domains are vital not only to local organisms within the transition habitat itself but also have strong effects on adjacent ecosystems (Wall et al. 2001). These transition regions are classified as critical zones and support communities with structural characteristics different from the two habitats they connect (Ewel et al. 2001, Wall et al. 2001). In addition, coastal areas are associated with large human populations, including the largest cities in the world, resulting in significant impacts on coastal ecosystems (Timmerman \& White 1997, Bulleri \& Chapman 2010). The construction of harbours, breakwaters, marinas and the pollution associated with these constructions can change the dynamics of benthic communities, homogenizing the environmental conditions (Dafforn et al. 2015, Mayer-Pinto et al. 2017) which result in communities with reduced diversity that are particularly difficult to manage (Ewel et al. 2001). Therefore, the understanding of ecological processes controlling community assembly and population dynamics in coastal areas is essential, not only to address basic ecological questions but also as a support for coastal planning, management and conservation.

Among coastal ecosystems, rocky shores are complex habitats with many studies investigating biotic and abiotic processes regulating the diversity, abundance and structure of biota (Menge 2000b, Jenkins et al. 2008) at different spatial scales (Navarrete et al. 2005, Burrows et al. 2009). Rocky shores support a diverse community of sessile organisms composed predominantly of barnacles, mussels, algae, bryozoans, and ascidians, which are distributed from the subtidal to the upper 
regions of the shore (Paine 1966, Russ 1982). This high diversity is partially sustained by an array of microhabitats distributed across an extreme environmental gradient from fully marine to fully terrestrial habitats (McGuinness \& Underwood 1986). The majority of sessile organisms present a complex life cycle with sessile adults and a planktonic dispersal stage, linked by a settlement event (Jackson 1977). Consequently, human interventions that modify the physical and biotic conditions in either the benthic or the pelagic habitat can affect larvae supply, recruitment, juvenile and adult mortality and therefore the population and community dynamics in these habitats (Abelson et al. 2005).

In south-eastern Brazil, Araçá Bay is a relatively shallow bay that has been modified by increasing expansion of the São Sebastião Port, one of the largest oil ports in Brazil. Araçá Bay supports a mosaic of distinct habitats, including sandy and rocky shores, mudflats and mangroves. As such it is a hot spot for diversity on the Brazilian Coast (Amaral et al. 2010). The entrance of the Bay is under the influence of the São Sebastião Channel, while the inner portions of it are strongly influenced by the inputs of the Mãe Isabel River, close to the Port. Hence organisms living along this environmental gradient, from sheltered inner areas to more exposed parts at the bay mouth, are probably subject to distinct regulating mechanisms. This assertion is evidenced by recent results, which show a distinct isotopic signature in algae and hermit crabs from the bay entrance to the inner area. Organisms living close to the coast are more affected by anthropogenic nitrogen pollution from the Mãe Isabel River (Gorman et al. 2017).

The diverse multi-habitat environment of Araçá Bay is threatened by the expansion of the São Sebastião Port; plans have been made to cover part of the Bay 
with suspended platforms. It has been shown that the restriction of light caused by the proposed construction can promote significant changes in the structure of rocky shore communities (Pardal-Souza et al. 2017). However such construction, in addition to causing shade, will bring a diverse range of other impacts, including physical disturbance, enhanced sedimentation and chemical pollution. We are currently not aware of the relative contribution of the mechanisms regulating populations and communities distributed along the Araçá Bay, and how they can respond to these anthropogenic modifications.

In this study we described the spatio-temporal dynamics of sessile communities from rocky shores in Araçá Bay over a 20 month period in three distinct regions: the inner portion, close to the Mãe Isabel River and the Port, the middle of Bay, and the outer region, close to the Bay entrance. Also, to test hypotheses regarding the influence of local environmental variation on the dynamics of key species, we experimentally tested how location along the gradient from the inner region to the outer mouth affects several aspects of the population of the barnacle Chthamalus bisinuatus. As barnacles are among the most abundant organisms in the intertidal zone of rocky shores around the world and several studies have shown that even small variation in oceanographic conditions such as flow speed, temperature, food concentration and quality can affect population dynamics (Sanford et al. 1994, Jenkins et al. 2000, Menge 2000a, Lagos et al. 2005), we used this model to better understand the importance of environment heterogeneity over small spatial scales to regulate populations in the Araçá Bay. 


\section{METHODS}

2.1. Structure of the sessile community in Araçá Bay

We sampled three rocky shores located in different regions of the Bay about 400 m apart from each other: (i) at the mouth of the bay, where it meets the São Sebastião Channel, (ii) in the middle and (iii) at the inner area of the northern side of the bay, close to the Port and a river discharge (Figure 1). The seawater circulation pattern inside the bay is tidally dominated, where dominant currents are cross-shore, with less expressive longshore components (Siegle et al. 2017). Rocky shores inside the bay are surrounded by a shallow mudflat rich in organic matter, as showed by the higher N:P proportion and Chl a concentration than the São Sebastião Channel (Giannini \& Ciotti 2016; Alcántara-Carrió et al. 2017). There is spatial variability in energy across the bay. The northern side presents the strongest currents, coinciding with the deepest and most dynamic area of the bay, while the more sheltered southern margin, the central area and southern inner portion of the bay are less dynamic, shallower and contain more subaerial exposed areas (Siegle et al. 2017). Considering the spatial distribution of the currents and bed shear stress in the bay, the most dynamic areas are those at the mouth of the bay and at its northern side, resulting in higher water exchange and particle transport (e.g. nutrients) (Siegle et al. 2017).

At each shore we delimited three strata in the intertidal zone: the supra-littoral fringe, dominated by the barnacle Chthamalus bisinuatus; the mid-littoral characterized by the presence of the barnacle Tetraclita stalactifera; and the infralittoral fringe, which is dominated by macroalgae. Because sand and mud cover the 
low strata of the inner rocky shore, sampling in this region was restricted to the supralittoral fringe.

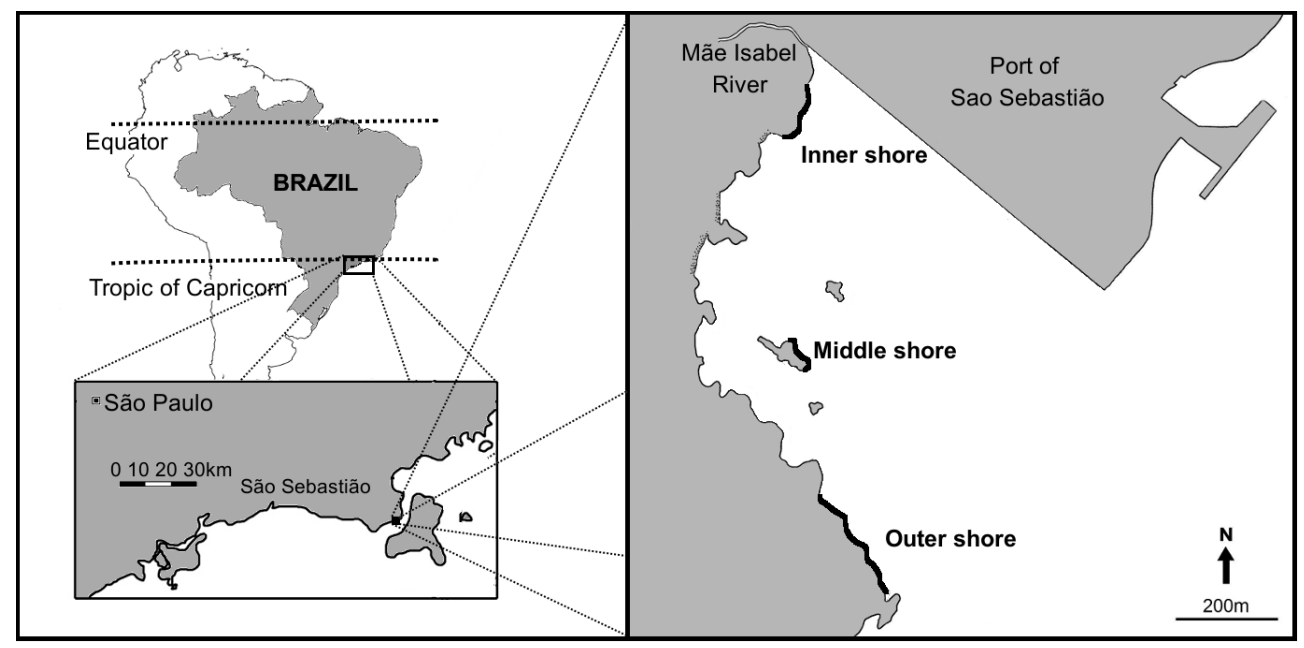

Fig1. Map of the Araçá Bay in Southeastern Brazil, showing the three sampled rocky shores: outer, middle and inner shore.

During each of five sampling events (October 2012, February, July and November 2013 and June 2014), we took pictures of 20 quadrats $(10 \times 10 \mathrm{~cm})$, haphazardly delimited $1 \mathrm{~m}$ apart from each other in each stratum of each rocky shore. Images were analyzed using the CPCe image analysis software with a grid of 100 intersections (Kohler and Gill 2006) to determine the area covered by each species.

For each stratum, we compared the community structure among regions (fixed factor) of Araçá Bay and sampling events (random factor) using a 2-way mixed model permutational analysis of variance, with 999 permutations based on a taxa-area coverage matrix, and using the Bray-Curtis distance among sampling units. Species responsible for the differences observed were assessed using a SIMPER analysis (Anderson 2001).

2.2. Population dynamics of the barnacle Chthamalus bisinuatus through Araçá Bay 
Initial analyses of communities suggested that the population structure of the barnacle $C$. bisinuatus differed from the outer to the inner shore of the Araçá Bay. We thus implemented a sampling design comparing barnacle size, density, recruitment rate, growth and survivorship across Araçá Bay combining a descriptive and an experimental approach.

To confirm our initial observations, we used the pictures obtained for community analyses to quantify density and size of $C$. bisinuatus. From each of the 20 pictures taken in the supra-littoral fringe of the three regions, we quantified the number of barnacles in $100 \mathrm{~cm}^{2}$ and then measured the opercular length in 10 randomly selected barnacles using the software Image J. Because we were interested to test the temporal consistency of size and density variation we conducted this analysis at the beginning (October 2012) and at the end of field sampling (June 2014). We then computed the average size per sample and compared size and density among locations using a two-way analysis of variance on log-transformed data, where location (inner, middle and outer shore) was a fixed factor and time (Oct/12 and Jun/14) was a random variable. A Tukey test was employed for pair-wise comparisons. Barnacle size data did not achieve normality and pre-requisite for parametric tests, while density data were heterocedastic. As we had equal sample sizes across locations and time and log-transformation did not improve data fit to parametric pre-requisites we still used a mixed model analysis on the raw data.

To compare the recruitment of $C$. bisinuatus among locations we utilized acrylic plates $(8 \times 8 \mathrm{~cm})$ covered with grey slip-resistant tape $\left(3 \mathrm{M}^{\mathrm{TM}}\right.$ Safety-Walk, Saint Paul, MN, USA). Ten plates were screwed in the supra-littoral fringe in each one of the locations (inner, middle and outer shore) and replaced approximately every 
30 days from May 2014 to May 2015. In the laboratory, we quantified recruits of $C$. bisinuatus under a stereomicroscope. Because we were interested in both spatial and temporal variation of recruitment we used a 2-way analysis of variance where both region and sampling period were fixed factors.

To assess how environmental differences between the outer and the inner regions of the bay and the associated co-variation in density of barnacles affected growth and survivorship of barnacles we conducted a transplant experiment. In February 2014 we removed all barnacles from sixty 10x10 cm areas located in the supra-littoral fringe at the outer shore. Two months later, following successful recruitment of $C$. bisinuatus to these cleared areas, we extracted fifty-six intact cylinders of rock of $5 \mathrm{~cm}$ of diameter and $3 \mathrm{~cm}$ depth using a core drill bit. Cores were moved to the lab, where they were kept in flowing seawater. We then quantified the number of recruits of barnacles on the surface of each rock core. In order to create a gradient of recruit density, from low to high, we manipulated barnacle density on some cores by randomly removing recruits. After 15 days, we divided cores into two groups of 28 with recruit density ranging from 3.2 to 21.2 barnacles $/ \mathrm{cm}^{2}$. One group was transplanted to the outer shore at the entrance of the Bay and one to the inner shore. In the outer shore, cores were inserted and glued into the open holes using the epoxy resin Tubolit such that the core surface was flush with the surrounding rock. At the inner bay, cores were glued in holes drilled in a similar manner to the outer site.

We then took pictures of each core at time 0 and after 30, 60, 120,150, 180, 210 and 270 days in the field. From the initial pictures we randomly selected 30 barnacles and measured the maximum operculum length of the barnacle as a proxy of barnacle size. In the following samplings, we searched for and measured the same 30 barnacles in the pictures to quantify 1) survivorship and 2) growth. We then compared 
barnacle survivorship and size through time between the two locations using a repeated measures analysis of variance. To describe how initial density of barnacles affect survivorship and relative size increment (\%), calculated as [(final size - initial size)/initial size] $x 100$, we used analyses of covariance, where location was the fixed factor, initial density of recruits the covariate and barnacle survivorship and size increment were the dependent variables.

\section{RESULTS}

\subsection{Community structure}

In the three studied rocky shores the supra-littoral fringe was dominated by the barnacle Chthamalus bisinuatus, which covered more than $40 \%$ of the available space in the outer shore, and $50 \%$ of the area in the inner shore. Communities in the inner portion of the Bay were always distinct from those at the middle (for all pairwise analyses $\mathrm{p}<0.05$ ) of the Bay but differed from the outer communities only in three of the five sampled periods (for pairwise analyses in Oct-12, Jul-13 and Nov-13 $p<0.05$ ) (Table 1). Differences among locations were always driven by $C$. bisinuatus and Brachidontes solisianus (SIMPER analysis) (Supplementary table 1). Temporal variation of the communities was driven mainly due the recruitment of the bivalve $B$. solisianus, which recruited in some periods mainly at the outer shore, and resulted in a time $\mathrm{x}$ location interaction (Table 1, Figure 2).

Table 1. PERMANOVA testing the effects of the sampling time (random) and region (fixed) on the structure of the sessile communities in the three studied strata from the Araçá Bay

\begin{tabular}{lrrrr}
\hline \multicolumn{5}{c}{ Supra-littoral fringe } \\
\hline Source & $\mathrm{df}$ & $\mathrm{MS}$ & Pseudo $\mathrm{F}$ & $\mathrm{p}$ \\
Time - T & 4 & 7949.7 & 26.23 & $<\mathbf{0 . 0 1}$ \\
Region - R & 2 & 3344.2 & 1.64 & 0.19 \\
\hline
\end{tabular}




\begin{tabular}{|c|c|c|c|c|}
\hline $\begin{array}{l}T^{*} R \\
\text { Error }\end{array}$ & $\begin{array}{r}8 \\
282 \\
\end{array}$ & $\begin{array}{r}2043.1 \\
303.1\end{array}$ & 6.74 & $<0.01$ \\
\hline \multicolumn{5}{|c|}{ Mid-littoral } \\
\hline & $\mathrm{df}$ & MS & Pseudo F & $\mathrm{p}$ \\
\hline Time - T & 4 & 16742.0 & 20.45 & $<0.01$ \\
\hline Region - R & 1 & 20661.0 & 5.12 & 0.06 \\
\hline$T *{ }^{*} R$ & 4 & 4064.4 & 4.96 & $<0.01$ \\
\hline Error & 180 & 818.7 & & \\
\hline \multicolumn{5}{|c|}{ Infra-littoral fringe } \\
\hline & $\mathrm{df}$ & MS & Pseudo F & $\mathrm{p}$ \\
\hline Time - T & 4 & 5074.0 & 9.00 & $<0.01$ \\
\hline Region - R & 1 & 6123.1 & 1.49 & 0.32 \\
\hline$T{ }^{*} R$ & 4 & 4095.3 & 7.27 & $<0.01$ \\
\hline Error & 186 & 563.5 & & \\
\hline
\end{tabular}



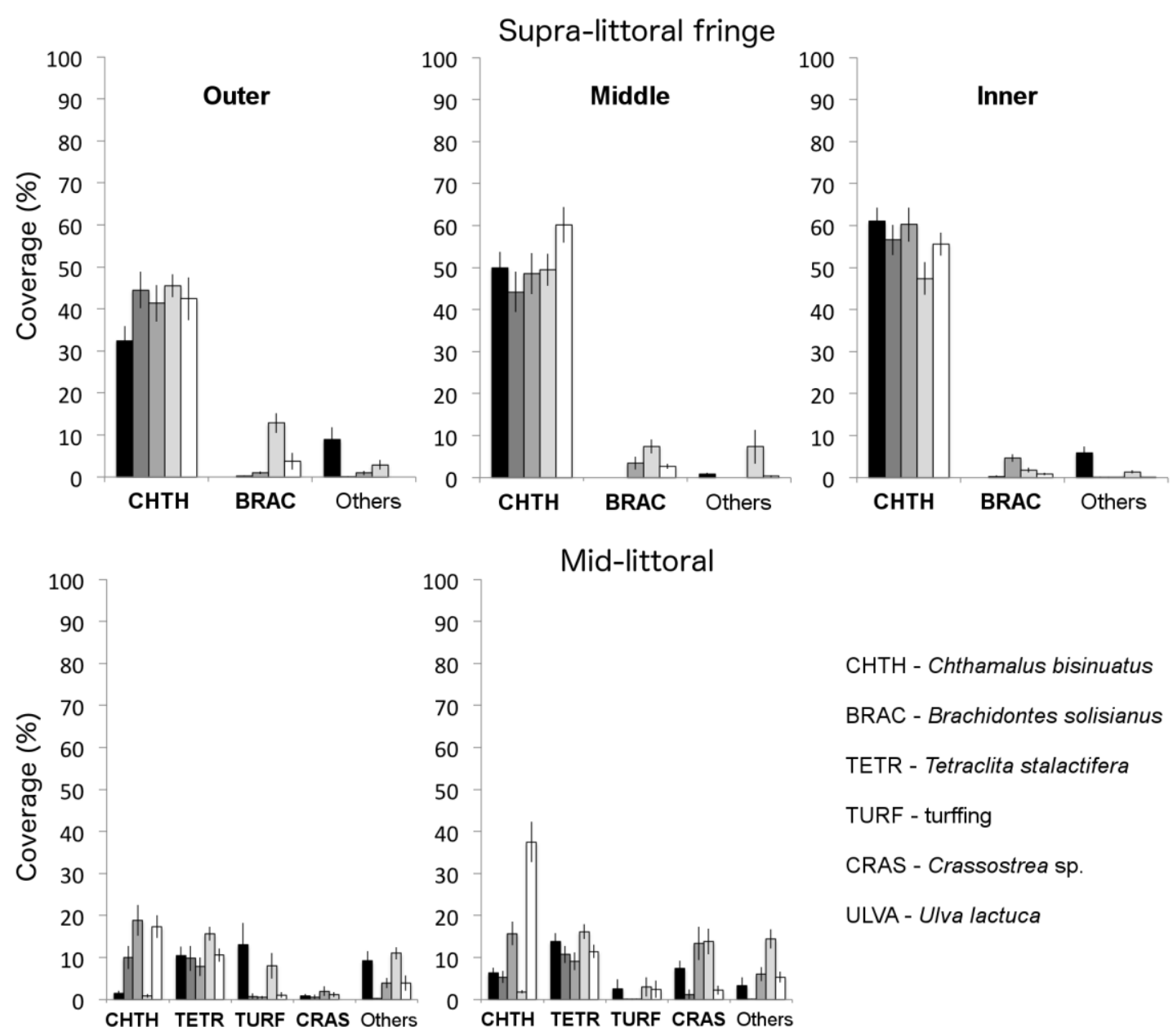

$$
\begin{aligned}
& \text { CHTH - Chthamalus bisinuatus } \\
& \text { BRAC - Brachidontes solisianus } \\
& \text { TETR - Tetraclita stalactifera } \\
& \text { TURF - turffing } \\
& \text { CRAS - Crassostrea sp. } \\
& \text { ULVA - Ulva lactuca }
\end{aligned}
$$
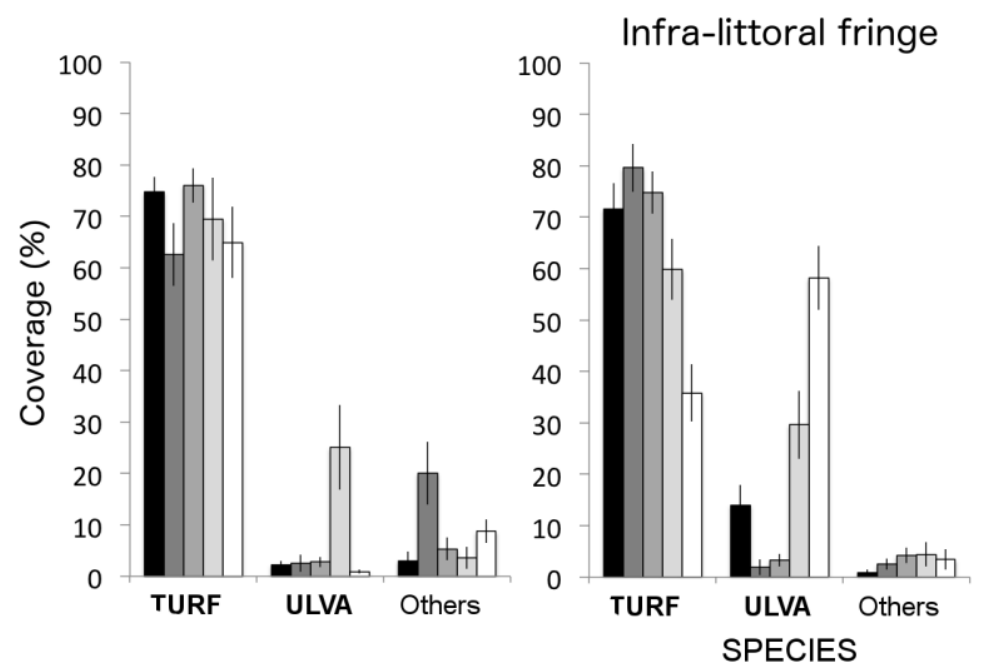

Fig2. Percentage coverage (average $\pm \mathrm{SE}$ ) of the main sessile organisms in the three studied heights of the outer, middle and outer shores. Different colors represent the five temporal sampling times, from black to white, respectively: October 2012, February, July and November 2013 and June 2014. 
In the mid-littoral, more than $70 \%$ of the available space was unoccupied during most of the study, and even the barnacle Tetraclita stalactifera, typical of this region, covered no more than $10 \%$ of the substrata. Communities from the middle shore differed from those of the outer shore in four of the five sampled periods (for pairwise analyses in Oct-12, Jul-13, Nov-13 and Jun-14 $\mathrm{p}<0.05$ ) resulting in a time $\mathrm{x}$ region interaction. The difference between shores was caused mainly by $C$. bisinuatus and by the oyster Crassostrea sp. that occupied a larger area in the mid shore during some periods of the year (Table 1, Figure 2) (Supplementary table 1).

The infra-littoral fringe was covered during the whole study by turfing macroalgae that occupied on average more than $60 \%$ of the available substrata, but communities from the middle and outer locations differed from each other in three of the five sampling moments (for pairwise analyses in Oct-12, Feb-13 and Jun-14 $p<$ 0.05). This difference between locations was caused mainly by the higher abundance of the macroalgae Ulva lactuca at the middle shore that in some periods of the year covered most of the available substrata (Figure 2, Table 1) (Supplementary table 1).

\subsection{Population dynamics of the barnacle Chthamalus bisinuatus in Araçá Bay}

The size of Chthamalus bisinuatus increased from the outer to the inner shore. Barnacles growing on the inner, middle and outer shores formed three distinct groups (Tukey test, $\mathrm{p}<0.05$ for all comparisons). In the opposite direction, the density of barnacles was higher at the outer location compared to the inner (Tukey test, $\mathrm{p}=0.02$ ). Density in the middle shore did not differ from that in the outer and inner shores (Tukey test, $\mathrm{p}>0.05$ for both comparisons) (Figure 3, Table 2). 
Table 2. Two-way ANOVA testing the effects of Time (random) and Region on the size and density of the barnacle Chthamalus bisinuatus

\begin{tabular}{lrrrrrrrrr}
\hline & \multicolumn{4}{c}{ Size } & & \multicolumn{4}{c}{ Density } \\
\cline { 2 - 7 } \cline { 7 - 9 } Source & $\mathrm{df}$ & $\mathrm{MS}$ & F-ratio & $\mathrm{p}$ & & $\mathrm{df}$ & $\mathrm{MS}$ & F-ratio & $\mathrm{p}$ \\
Time & 1 & 14.62 & 91.76 & $<\mathbf{0 . 0 1}$ & & 1 & 4.69 & 2.04 & 0.16 \\
Region & 2 & 23.46 & 52.02 & $\mathbf{0 . 0 2}$ & & 2 & 8.95 & 24.06 & $\mathbf{0 . 0 4}$ \\
Time * $^{*}$ Region & 2 & 0.45 & 2.83 & 0.06 & & 2 & 0.37 & 0.16 & 0.85 \\
Error & 114 & 0.16 & & & & 114 & 2.30 & & \\
\hline
\end{tabular}
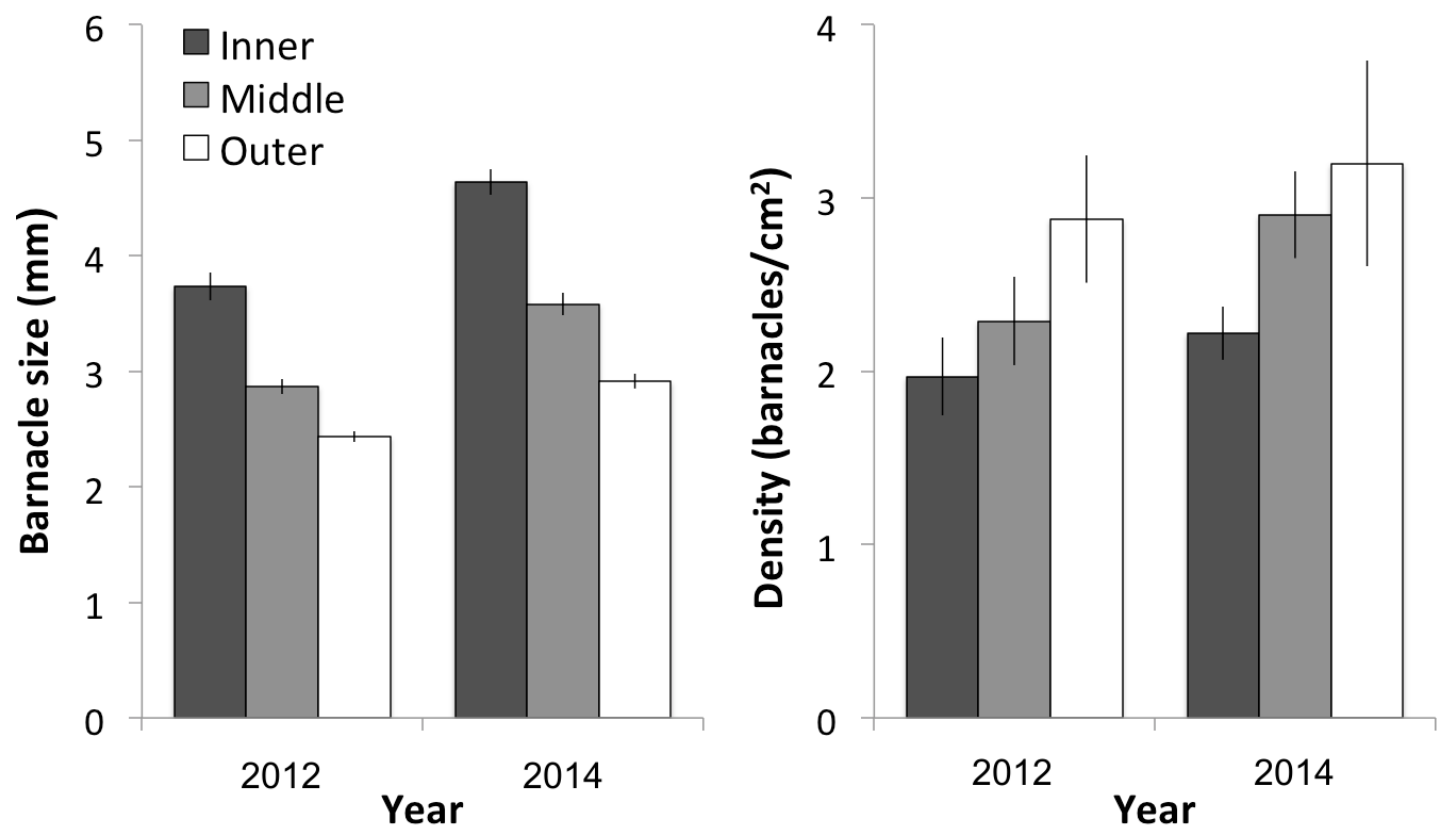

Fig3. Size and density (average \pm SE) of the barnacle Chthamalus bisinuatus in the three rocky shores (outer, middle and inner) along the Araçá Bay, Brazil in 2012 and 2014.

Recruitment of $C$. bisinuatus, measured using the settlement panels, was restricted to the period between March 2014 and May 2015. At peak recruitment more than 1.39 recruits were registered per $\mathrm{cm}^{2}$ at the outer location. However, recruitment was also extremely variable in space and even during peak of recruitment at the outer 
shore, recruits were absent or very scarce at the inner and middle shores (Figure 4, Table 3).

Table 3. Two-way ANOVA testing the effects of Region and Month on the recruitment of the barnacle Chthamalus bisinuatus

\begin{tabular}{lrrrr}
\hline Source & df & MS & F-ratio & $p$ \\
Region & 2 & 8.68 & 68.29 & $<\mathbf{0 . 0 0 1}$ \\
Month & 9 & 3.28 & 25.82 & $<\mathbf{0 . 0 0 1}$ \\
Region * Month & 18 & 0.41 & 3.23 & $<\mathbf{0 . 0 0 1}$ \\
Error & 256 & 0.13 & & \\
\hline
\end{tabular}

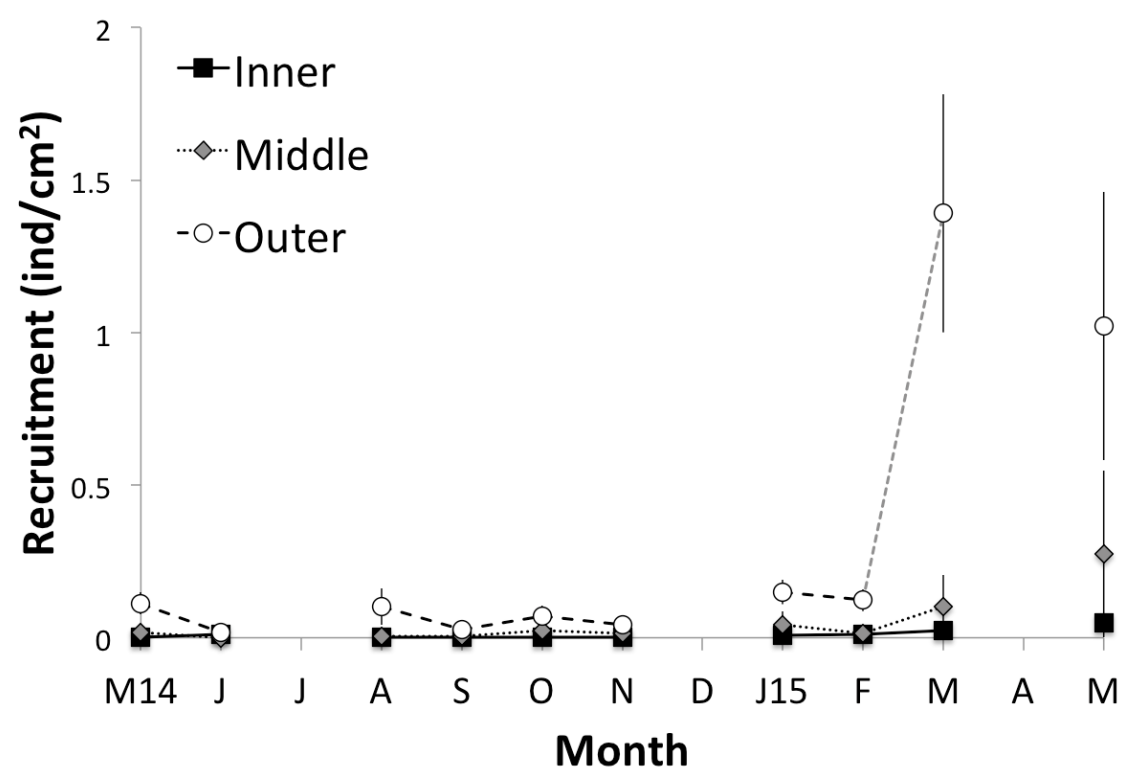

Fig4. Recruitment (average $\pm \mathrm{SE}$ ) of the barnacle Chthamalus bisinuatus in the three rocky shores (outer, middle and inner) along the Araçá Bay, Brazil from May 2014 to May 2015.

Regarding the translocation experiment, barnacles at the inner shore showed higher levels of survival than those growing at the outer shore. After 270 days, overall survival across all barnacle densities was 3.5 higher in the inner shore than in the outer shore (Figure 5A, Table 4). There was a significant negative relationship between initial recruit density and percent survival 270 days later (Figure 5B) which was consistent between locations (no significant Location x Density interaction Table 
5). There was a clear significant effect of location on percent survival. This effect was large. Barnacles growing at initial densities close to 21 individuals $/ \mathrm{cm}^{2}$ (maximal levels in the experiment) were $30 \%$ more likely to die than those growing in areas with minimal densities ( 2 individuals $/ \mathrm{cm}^{2}$ ). Differences between the inner and the outer shore also affected barnacle growth. Barnacles growing at the inner shore were $23 \%$ larger than those at the outer shores after 270 days (Figure 5C, Table 4). As for survivorship, barnacle density also affected negatively $C$. bisinuatus growth. Individuals growing at low densities grew 2 times larger than those at high densities, but no region effect was observed (Figure 5D, Table 5).

Table 4. Repeated measure ANOVA testing the effects of Region and Time on survivorship and size of the barnacle Chthamalus bisinuatus

\begin{tabular}{|c|c|c|c|c|c|c|c|c|}
\hline \multirow[b]{2}{*}{ Source } & \multicolumn{4}{|c|}{ Survivorship } & \multicolumn{4}{|c|}{ Size } \\
\hline & df & MS & F-ratio & $P$ value & df & MS & F-ratio & $P$ value \\
\hline Region & 1 & 9.98 & 62.82 & $<0.001$ & 1 & 4.55 & 34.94 & $<0.001$ \\
\hline Error & 53 & 0.16 & & & 23 & 0.13 & & \\
\hline Time & 5 & 2.33 & 109.68 & $<0.001$ & 7 & 4.29 & 371.62 & $<0.001$ \\
\hline Time * Region & 5 & 0.59 & 27.74 & $<0.001$ & 7 & 0.14 & 12.16 & $<0.001$ \\
\hline Error & 265 & 0.02 & & & 161 & 0.01 & & \\
\hline
\end{tabular}

Table 5. Analyses of covariance (ANCOVA) testing the effects of initial density and region on the final survivorship and relative growth of the barnacle Chthamalus bisinuatus

\begin{tabular}{lrrrrrrrrrr}
\hline & \multicolumn{4}{c}{ Survivorship } & & \multicolumn{4}{c}{ Relative growth } \\
\cline { 2 - 4 } \cline { 7 - 9 } Source & df & MS & F-ratio & P value & & df & MS & F-ratio & P value \\
Region & 1 & 0.56 & 9.43 & $\mathbf{0 . 0 1}$ & & 1 & 0.01 & 0.15 & 0.70 \\
Density & 1 & 0.30 & 5.05 & $\mathbf{0 . 0 3}$ & & 1 & 0.53 & 9.58 & $\mathbf{0 . 0 1}$ \\
Reg * Dens & 1 & 0.01 & 0.09 & 0.77 & & 1 & 0.02 & 0.39 & 0.53 \\
Error & 51 & 0.06 & & & & 34 & 0.06 & & \\
\hline
\end{tabular}



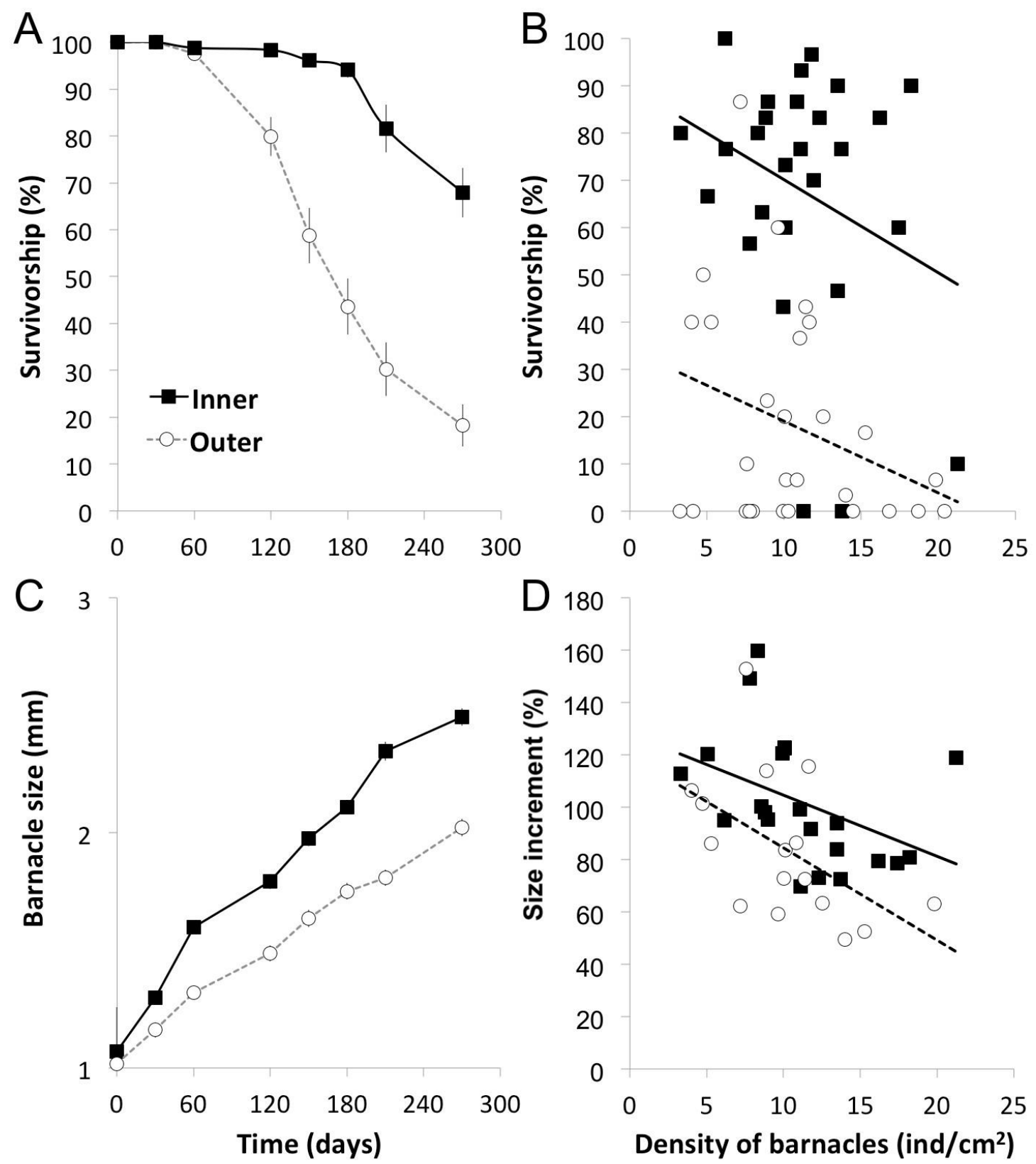

D 180
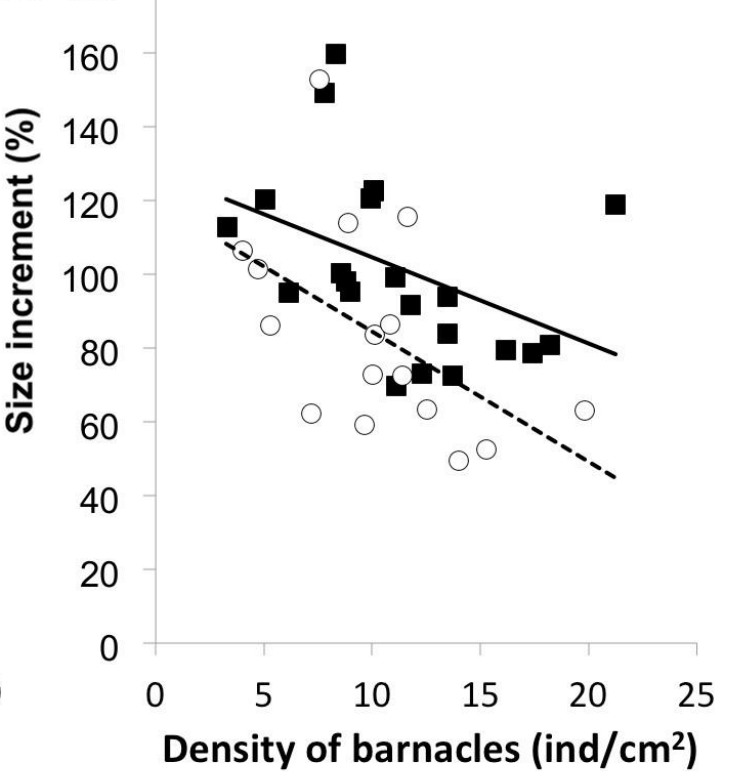

Fig5. A) Survivorship (average $\pm \mathrm{SE}$ ) of the barnacle Chthamalus bisinuatus in the outer and inner shores along the sampling period and B) Effect of initial density and region on the final survivorship of $C$. bisinuatus. C) Chthamalus bisinuatus size in the outer and inner shores along the sampling period and D) Effect of initial density and region on the relative size increment (\%) of $C$. bisinuatus. 


\section{DISCUSSION}

In our study we show the importance of small spatial scale variability driving the dynamics of populations and communities. While sessile communities have the same species composition throughout Araçá Bay, the dynamics of the communities at the three different sites diverge despite being only hundred meters apart. These observations confirm that an important environmental gradient operates within Araçá Bay from terrestrial/freshwater input in the inner bay to a predominantly marine environment of the São Sebastião Channel at the outer bay. An obvious example of the consequences of the variation of conditions along this gradient is the higher occupation of substrata by the barnacle Chthamalus bisinuatus at the inner shore. The dynamics of barnacle populations are controlled by several physical and biological processes, which can affect recruitment, mortality and growth of individuals (Menge 2000a; Jenkins et al 2008b), making populations only a few kilometres apart completely distinct (Lagos et al. 2005). In our study, the differences in coverage among shores, hundreds meter apart, was the result of the large size of barnacles at the inner region of the bay, where recruitment was restricted but mortality was very low and growth was much faster than in the outer shores. So the differences in the processes regulating barnacle population scaled up to determine the structure of the community in the supra-litoral fringe. While the methods used to describe the communities here prevent us to discuss spatial turnover of species along the bay, our results show that the Araçá Bay is highly heterogeneous regarding the processes regulating sessile communities, as expected for regions that function as transition zones between distinct habitats (Wall et al. 2001). 
For all the strata, there was a spatio-temporal variation of the structure of the communities. This variation was caused mainly by the change in the size of the population of the most common species throughout the bay in some periods of the year. In the infra-littoral fringe of the middle shore, from our third sampling during the winter of 2013, until the end of the study in the winter of 2014, the area occupied by the macroalgae Ulva lactuca increased, restricting the occurrence of the turfing of algae to small patches underneath. The dynamic of ephemeral algae in the São Sebastião Channel is controlled by nutrient inputs driven by wave exposure and grazing (Flores et al. 2015). In the Araçá Bay, during the wet season, riverine inputs from the Mãe Isabel river result in a gradient of nutrients within the bay (Dottori et al. 2015) with a proportion of dissolved inorganic nitrogen from the inner to the outer portions of the bay of $6: 1$ (SABESP 2015, Gorman et al. 2017). Considering that the top-down influence would be constant over time, this increase in the amount of nitrogen at inner portions of the bay can boost $U$. lactuca growth in the middle shore, which remained as the dominant species in the community even during the next cold/dry season, when storms and cold fronts increase the entrance of water from the São Sebastião Channel, mixing the water column into the bay (Mazzuco et al 2015, Gorman et al. 2017).

Ulva species are tolerant to both organic and inorganic pollution and have been used as a bioindicators of metal and organic pollution in several parts of the world (Ho 1990, Malea \& Haritonidis 2000, Villares et al. 2001), including in Brazil (Mayer-Pinto \& Junqueira 2003). In the Araçá Bay, the isotopic signal of Ulva lactuca shows a quick change during the wet periods and a reduction in the influence of anthropogenic nitrogen pollution from the bottom to the entrance of the Bay (Gorman et al. 2017). So the differences in the relative abundance of species among 
shores during some periods of the year could be the result of the variation in the intensity of the gradient created by the inputs of Mãe Isabel River and pelagic processes at the São Sebastião Channel. It can also explain the larger abundance of the oyster Crassotrea sp., a species usually found in mangrove roots and brackish water, in the middle shore, when compared to communities at the entrance of the bay.

Several studies show that the dynamics of barnacle populations are highly variable at a variety of scales (Jenkins et al. 2000, O'Riordan et al. 2004) and processes operating at distinct life-stages from larval supply to juvenile and adult survival can affect the dynamics of populations (Gosselin \& Qian 1997, Hughes et al. 2000). The variation in conditions throughout Araçá Bay seems to affect both pre and post recruitment processes resulting in distinct dynamics of Chthamalus bisinuatus populations, even at a scale of few hundred meters. The small density of barnacles in the inner shore suggest that populations here are recruit-limited. Whilst Barbosa et al (2016) argue that larval settlement in C bisinuatus may be regulated by local reproductive output (which could be expected to be high at the inner site owing to the large size of individuals) it seems that local hydrodynamics probably don't facilitate local retention at this scale. At the middle and especially outer sites recruitment is probably enhanced by supply of larva from within the bay and the wider environment of the São Sebastião Channel. Greater water flow at these sites may intensify recruitment as demonstrated for other barnacle species (e.g. Burrows et al. 2010). In addition, for some barnacle species, cypris attachment can be negatively affected by low salinity (Thiyagarajan et al. 2003), so besides a lower larval supply and low water flow, the freshwater input at the inner portion of the bay can reduce survivorship of larvae and explain the restricted settlement and the low density of individuals in the natural substrata at this location. 
For those larvae that can reach the inner shores, post-settlement mortality is low and growth is much higher than at shores close to the São Sebastião Channel. The differences in the density of conspecifics throughout the Araçá Bay, caused by the differential recruitment, can create a gradient of conspecific competition that increases in the opposite direction of the physical stresses, as usually described for organisms in the intertidal zone (Connell 1961). It could explain why barnacle survivorship and growth are lower at the outer shores, where recruitment is more intense. When we standardized the density of competitors during the translocation experiment, mortality at both outer and inner shore was similar during 90 days, with a clear increase in mortality in the outer shore from that moment on, probably due to recruitment of new individuals in the plots observed at that time, which increased density and competition. In the inner shore, the low recruitment rate, the enhanced input of anthropogenic nutrients by the Mãe Isabel River and the higher pelagic dynamic at the northern side due to higher water exchange and transport from mudflat components (e.g. nutrients, organic matter) (Gorman et al. 2017; Siegle et al. 2017), provide better conditions for barnacle survivorship

The Araçá Bay seems to create a gradient of environmental conditions that affect in distinct ways the life-stages of organisms living within different portions of it. Using the population of Chthamalus bisinuatus to describe the variation among shores in Araçá Bay, we could classify the outer shore as more dynamic with a large turnover of bare space and dependent on oceanographic processes operating outside of the bay, making this region more resilient to future localized anthropogenic disturbances. In the opposite direction, the inner portion of the Araçá Bay, where most of the sources of disturbances are concentrated, as a consequence of the Port of São Sebastião and the input of untreated sewage through the Mãe Isabel River, is 
potentially more sensitive to anthropogenic impacts since the supply of new individuals after disturbances is restricted. In addition to that, there are differences in bathymetry and soft sediment composition and organic matter content into the bay, where the inner region is shallow and richer in organic matter than the outer region (Corte et al. 2017). As the tidal range in this region is about $1 \mathrm{~m}$, changes in the bathymetry of only 30 to $50 \mathrm{~cm}$ represent an important variation in the vertical gradient and distance from the supra-littoral zone to the soft bottom region. We can suggest an interactive effect of nutrients and hydrodynamics driven bottom up processes as was shown in rocky shores in the São Sebastião Channel (Flores et al. 2015). In this context, pelagic enrichment in nutrients from the soft sediment disturbance during the flood tide increases the food available for the filter feeding animals in the Araçá Bay. Thus attempts to predict and mediate the consequences of anthropogenic disturbances, such as the expansion of the Port of São Sebastião in the Araçá Bay, must consider that in transition zones such as the one studied here, the processes regulating the dynamics of populations and communities can change over scales of tens to hundreds of meters and also due to any changes in the bathymetry of this region.

In addition to the contribution toward the specific case regarding management of Araçá Bay and the discussion of port expansion, our study contributes to the understanding of how small-scale processes can affect the dynamics of barnacle populations, a key species for the intertidal community. In our study, the understanding of processes leading to changes in recruitment, growth and mortality over hundreds of meters support a better understanding of how changes in flow, bathymetry and sewage input can drive the dynamics of rocky shore populations, and hence functioning of the ecosystem. Such experiments which tease apart the influence 
of physical, biological and anthropogenic factors within a local context of impact and management are important both for the management and conservation at this local scale and also as support for wider applications. In the local context, it is clear that changes in the seawater flow or productivity due to the port expansion in Araçá Bay will affect the recruitment, mortality and growth of key intertidal species with consequences for ecosystem functioning. In addition, the question of how generally applicable local scale understanding of ecological processes is to the wider world is one that has assumed primary importance. In our study, we used barnacles as an ecological model expanding the implications of these local results for regional and latitudinal scales. Barnacles are key organisms in the intertidal rocky shores over the entire world, regardless of taxonomic differences. By using barnacles as a bioindicator, our study supports researchers and decision makers from different regions to use such results for a better understanding of the ecology and management of intertidal areas with similar pressures. In this case, the linkage of similar situations of biodiversity, human impact and management challenges in different parts of the world would increase the implications of local scale results, allowing for better coastal planning and conservation.

\section{AKNOWLEDGMENTS}

This work was supported by research funds granted by São Paulo Research Foundation (FAPESP) to R.A.C. to support a visiting researcher awards to SJ (\#2013/11594-9; \#2015/50395-7) and to Biota Araçá Project (\#2011/50317-5). We

thank André Pardal-Souza, Felipe Oricchio, Felipe Dutra with field work and Centro de Biologia Marinha (CEBIMar-USP) for logistical support. 


\section{REFERENCES}

Abelson A, Olinky R, Gaines S (2005) Coral recruitment to the reefs of Eilat, Red Sea: temporal and spatial variation, and possible effects of anthropogenic disturbances. Marine Pollution Bulletin 50:576-582

Alcántara-Carrió J, Sasaki DK, Mahiques MM, Taborda R, Souza LAP (2017) Sedimentary constraints on the development of a narrow deep strait (São Sebastião Channel, SE Brazil). Geo-Marine Letters 37:475-488

Amaral A, Migotto A, Turra A, Schaeffer-Novelli Y (2010) Araca: biodiversity, impacts and threats. Biota Neotropica 10:219-264

Anderson MJ (2001) A new method for non-parametric multivariate analysis of variance. Austral Ecology 26:32-46

Barbosa ACC, Gomes CC, Pereira GC, Bueno M, Flores AA (2016) Local biological drivers, not remote forcing, predict settlement rate to a subtropical barnacle population. Marine Ecology Progress Series 543: 201-208

Bulleri F, Chapman MG (2010) The introduction of coastal infrastructure as a driver of change in marine environments. Journal of Applied Ecology 47:26-35

Burrows MT, Harvey R, Robb L, Poloczanska E, Mieszkowska N, Moore P, Leaper R, Hawkins S, Benedetti-Cecchi L (2009) Spatial scales of variance in abundance of intertidal species: effects of region, dispersal mode, and trophic level. Ecology 90:1242-1254

Burrows MT, Jenkins SR, Robb L, Harvey R (2010) Spatial variation in size and density of adult and post-settlement Semibalanus balanoides: effects of oceanographic and local conditions. Marine Ecology Progress Series 398: 207-219 
Corte GN, Checon HH, Fonseca G, Vieira DC, Gallucci F, Di Domenico M, Amaral ACZ (2017) Cross-taxon congruence in benthic communities: searching for surrogates in marine sediments. Ecological indicators 78:173-182

Connell J (1961) Influence of interspecific competition and other factors on distribution of barnacle Chthamalus stellatus. Ecology 42:710-723

Dafforn K, Glasby T, Airoldi L, Rivero N, Mayer-Pinto M, Johnston E (2015) Marine urbanization: an ecological framework for designing multifunctional artificial structures. Frontiers in Ecology and the Environment 13:82-90

Dottori M, Siegle E, Castro B (2015) Hydrodynamics and water properties at the entrance of Araçá Bay, Brazil. Ocean Dynamics 65:1731-1741

Ewel K, Cressa C, Kneib R, Lake P, Levin L, Palmer M, Snelgrove P, Wall D (2001) Managing critical transition zones. Ecosystems 4:452-460

Flores A, Christofoletti R, Peres A, Ciotti A, Navarrete S (2015) Interactive effects of grazing and environmental stress on macroalgal biomass in subtropical rocky shores: Modulation of bottom-up inputs by wave action. Journal of Experimental Marine Biology and Ecology 463:39-48

Giannini MFC, Ciotti AM (2016) Parameterization of natural phytoplankton photophysiology: Effects of cell size and nutrient concentration. Limnology and Oceanography 61: 1495-1512

Gorman D, Turra A, Connolly RM, Olds AD, Schlacher TA (2017) Monitoring nitrogen pollution in seasonally-pulsed coastal waters requires judicious choice of indicator species. Marine Pollution Bulletin in press

Gosselin LA, Qian PY (1997) Juvenile mortality in benthic marine invertebrates. Marine Ecology-Progress Series 146:265-282 
Ho Y (1990) Ulva lactuca as bioindicator of metal contamination in intertidal waters in Hong-Kong. Hydrobiologia 203:73-81

Hughes TP, Baird AH, Dinsdale EA, Moltschaniwskyj NA, Pratchett MS, Tanner JE, Willis BL (2000) Supply-side ecology works both ways: The link between benthic adults, fecundity, and larval recruits. Ecology 81:2241-2249

Jackson JBC (1977) Competition on marine hard substrata - adaptive significance of solitary and colonial strategies. American Naturalist 111:743-767

Jenkins S, Aberg P, Cervin G, Coleman R, Delany J, Della Santina P, Hawkins S, LaCroix E, Myers A, Lindegarth M, Power A, Roberts M, Hartnoll R (2000) Spatial and temporal variation in settlement and recruitment of the intertidal barnacle Semibalanus balanoides (L.) (Crustacea : Cirripedia) over a European scale. Journal of Experimental Marine Biology and Ecology 243:209-225

Jenkins S, Moore P, Burrows M, Garbary D, Hawkins S, Ingolfsson A, Sebens K, Snelgrove P, Wethey D, Woodin S (2008) Comparative ecology of North Atlantic shores: do differences in players matter for process? Ecology 89:S3S23

Jenkins SR, Murua J, Burrows MT, 2008 Temporal changes in the strength of density-dependent mortality and growth in intertidal barnacles Journal of Animal Ecology 77: 573-584

Kohler KE, Gill SM (2006). Coral Point Count with Excel extensions (CPCe): a Visual Basic program for the determination of coral and substrate coverage using random point count methodology. Computers and Geoscience 32: 12591269 
Lagos N, Navarrete S, Veliz F, Masuero A, Castilla J (2005) Meso-scale spatial variation in settlement and recruitment of intertidal barnacles along the coast of central Chile. Marine Ecology Progress Series 290:165-178

Malea P, Haritonidis S (2000) Use of the green alga Ulva rigida C. Agardh as an indicator species to reassess metal pollution in the Thermaikos Gulf, Greece, after 13 years. Journal of Applied Phycology 12:169-176

Mayer-Pinto M, Johnston E, Bugnot A, Glasby T, Airoldi L, Mitchell A, Dafforn K (2017) Building 'blue': An eco-engineering framework for foreshore developments. Journal of Environmental Management 189:109-114

Mayer-Pinto M, Junqueira A (2003) Effects of organic pollution on the initial development of fouling communities in a tropical bay, Brazil. Marine Pollution Bulletin 46:1495-1503

Mazzuco, ACA, Christofoletti RA, Pineda J, Starczak VR, Ciotti AM (2015) Temporal variation in intertidal community recruitment and its relationships to physical forcings, chlorophyll-a concentration and sea surface temperature. Marine Biology 162:1705-1725.

McGuinness K, Underwood A (1986) Habitat structure and the nature of communities on intertidal boulders. Journal of Experimental Marine Biology and Ecology 104:97-123

Menge B (2000a) Recruitment vs. postrecruitment processes as determinants of barnacle population abundance. Ecological Monographs 70:265-288

Menge B (2000b) Top-down and bottom-up community regulation in marine rocky intertidal habitats. Journal of Experimental Marine Biology and Ecology 250:257-289 
Navarrete S, Wieters E, Broitman B, Castilla J (2005) Scales of benthic-pelagic and the intensity of species interactions: From recruitment limitation to top-down control. Proceedings of the National Academy of Sciences of the United States of America 102:18046-18051

O'Riordan R, Arenas F, Arrontes J, Castro J, Cruz T, Delany J, Martinez B, Fernandez C, Hawkins S, McGrath D, Myers A, Oliveros J, Pannacciulli F, Power A, Relini G, Rico J, Silva T (2004) Spatial variation in the recruitment of the intertidal barnacles Chthamalus montagui southward and Chthamalus stellatus (Poli) (Crustacea: Cirripedia) over an European scale. Journal of Experimental Marine Biology and Ecology 304:243-264

Paine RT (1966) Food Web Complexity and Species Diversity. American Naturalist $100: 65-75$

Pardal-Souza A, Dias G, Jenkins S, Ciotti A, Christofoletti R (2017) Shading impacts by coastal infrastructure on biological communities from subtropical rocky shores. Journal of Applied Ecology 54:826-835

Russ GR (1982) Overgrowth in a Marine Epifaunal Community - Competitive Hierarchies and Competitive Networks. Oecologia 53:12-19

SABESP, 2015. Companhia de Saneamento Básico do Estado de São Paulo. Relatório de monitoramento do Emissários Submarinos, São Paulo.

Sanford E, Bermudez D, Bertness M, Gaines S (1994) Flow, food-supply and acorn barnacle population dynamics. Marine Ecology Progress Series 104:49-62

Siegle E, Dottori M, Vilamarin B (2017) Hydrodynamics of a subtropical tidal flat: Araça Bay, Brazil. http://dx.doi.org/10.1016/j.ocecoaman.2017.11.003. 
Thiyagarajan V, Harder T, Qiu J, Qian P (2003) Energy content at metamorphosis and growth rate of the early juvenile barnacle Balanus amphitrite. Marine Biology $143: 543-554$

Timmerman P, White R (1997) Megahydropolis: coastal cities in the context of global environmental change. Global Environmental Change-Human and Policy Dimensions 7:205-234

Villares R, Puente X, Carballeira A (2001) Ulva and Enteromorpha as indicators of heavy metal pollution. Hydrobiologia 462:221-232

Wall D, Palmer M, Snelgrove P (2001) Biodiversity in critical transition zones between terrestrial, freshwater, and marine soils and sediments: Processes, linkages, and management implications. Ecosystems 4:418-420 